\title{
Determinants affecting utilisation of health services and treatment for children under-5 in rural Nepali health centres: a retrospective cohort study
}

\author{
Binod Shrestha \\ PHASE Nepal \\ Dan Green ( $\nabla$ d.j.green@sheffield.ac.uk) \\ University of Sheffield \\ Manish Baidya \\ PHASE Nepal \\ Tim Chater \\ University of Liverpool \\ Jiban Karki \\ University of Sheffield \\ Andrew Lee \\ University of Sheffield \\ Seema Khadka \\ PHASE Nepal \\ Gerda Pohl \\ PHASE Nepal \\ Rudra Neupane \\ PHASE Nepal \\ Simon Rushton \\ University of Sheffield
}

\section{Research Article}

Keywords: Nepal, social inequalities, health inequalities, child health, treatment, health-seeking behaviour, global health

Posted Date: January 12th, 2022

DOI: https://doi.org/10.21203/rs.3.rs-1250288/v1

License: (c) (i) This work is licensed under a Creative Commons Attribution 4.0 International License. Read Full License 


\section{Abstract}

Background: Large inequalities in child health remain in Nepal, with caste, ethnicity and sex being major determinants of deprivation and negative outcomes. The purpose of this study was to explore whether key demographics on under $5 s$ were associated with health seeking behaviours, utilisation of health care, and treatment received.

Methods: Data came from Integrated Management of Neonatal \& Childhood IIIness (IMNCI) records of 23 health centres across five districts. After digitising the paper records, district, ethnicity, sex, age and temperature of the child were used to predict the number of days taken to seek medical care for Acute Respiratory Infection (ARI), diarrhoea and fever. In addition to this, correct diagnosis and subsequent treatment of pneumonia was assessed against IMNCl guidelines, again using the demographic factors of interest to predict these outcomes.

Results: From 116 register books spanning 23 health centres, 33,860 child patient records were considered for analysis. The median age of attendance was 16 months (Inter-Quartile Range= 9, 30), while there were more male children that attended ( $55.8 \%$ vs. $44.2 \%$ for females). There were statistically significant differences for the time taken to attend a health centre between different districts for ARI, diarrhoea and fever, with children in the remote Humla and Mugu districts taking significantly longer to present at a health facility after the onset of symptoms (all $p<0.012$ ). Children from underprivileged ethnic groups, Madhesi and Dalit, were less likely to be given a correct diagnosis of pneumonia $(p=0.001)$, while males were more likely to receive a correct diagnosis than females ( $73 \%$ vs. $67 \%, p=0.001)$. This sex difference remained in the adjusted regression models for diagnosis of pneumonia $(p=0.011)$ but not for treatment of pneumonia $(p=0.202)$.

Conclusions: Significant demographic differences were found based on ethnicity, sex, and district when examining health seeking behaviours for ARI, diarrhoea, and fever. Significant associations were seen for these same factors when exploring accuracy of diagnoses of pneumonia, but not for treatment. This study has emphasised the importance of a digitalised healthcare system, where inequalities can be identified without the reliance on anecdotal evidence.

\section{Background}

Despite considerable government efforts in recent years, Nepal continues to have huge social and geographic inequalities in child health. Nepal currently ranks 110th on the United Nations Development Programme's Gender Inequality Index [1], with caste and ethnicity continuing to be major determinants of poverty, education and health outcomes [2-5]. There are significant inequalities in access to and utilisation of basic health services between urban and rural areas, as well as between lowland, hill and mountain zones [2, 3, 5-7]. This presents a significant challenge for Nepal in terms of promoting social and economic development, meeting the Sustainable Development Goals to end preventable deaths of newborns and children under 5 years of age, and achieving universal health coverage.

Although work with the support of the World Health Organisation (WHO) on implementing an electronic health management and information system (HMIS) is ongoing, one major shortcoming of current health data in Nepal is that individual patientlevel data is not available at the government level: only aggregated data are reported from health facilities to the relevant provincial government. In large part, this is because health facilities, especially those in rural areas where infrastructure and capacity is lacking, continue to rely on paper-based health records which are never digitised. Consequently, individual patient records cannot easily be investigated for health outcome correlations with gender, ethnicity and caste [7]. For the same reason, there is a significant data gap that prevents monitoring and evaluation of the practices of front-line health workers, such as the extent to which they comply with treatment guidelines $[7,8]$.

Recognition of how inequalities affect health status, health service utilisation, and treatment provided, and the extent to which current health worker practices either mitigate or reinforce those inequalities, is highly pertinent for academic, policy and practice audiences. A good understanding of the impacts of inequality on health-seeking behaviours and healthcare will allow for the co-production of better policy and practice recommendations. This study sought to explore how age, sex, ethnicity and caste of young children affect: 1) their health-seeking behaviours and utilisation of health services; and 2) the treatment that 
they receive at health centres, with a particular focus on diagnosis and prescribing practices. A secondary objective of the study was to examine the utility of health data that is routinely collected by rural health centres.

\section{Methods}

The study was carried out by a team of researchers from the University of Sheffield in partnership with a Nepali nongovernmental organisation (NGO), PHASE Nepal, which works in remote Himalayan communities to support health, education and livelihoods. We conducted a retrospective analysis of health data that is routinely recorded by rural health centres.

\section{Setting}

In this study we collected data from 23 health centres across 5 Districts, all of which are in the Hill or Mountain zones of Nepal; Bajura, Humla and Mugu in the Far West of the country, and the central districts of Gorkha and Sindhupalchok. The three districts in the Far West are very remote with limited road access, services, and amenities. Wealth quintiles and literacy rates vary significantly between the two regions. About half of the population in the Far West lives below the poverty line. The Far West region has complex socio-economic structures and there is widespread gender- and caste-based discrimination. The central region is more varied, being home to various ethnic communities including Newar, Tamang, and Brahmins as well as different religions, including Hinduism, Buddhism and Islam. Levels of gender- and caste-based discrimination vary widely between different communities. All district headquarters in the central region have road connectivity, but geographical isolation, vulnerable roads and a lack of bridges across many rivers are nevertheless major challenges in the central region.

\section{Data collection}

The data for this project comes from information recorded and stored as paper records at 23 health centres supported (or previously supported) by PHASE Nepal. Research Assistants visited each of these centres to collect the data. The paper records were either digitally photographed and transported on secure electronic media to the PHASE Nepal office in the Kathmandu valley, or the record books themselves were taken to the PHASE Nepal office, photocopied, and returned to the health centres. All records were stored securely at the PHASE Nepal offices, as per the project's Data Management Plan.

\section{Description of data}

The record books utilised in this study record individual patient contacts for children under 5 years of age. The format of the record books follows the WHO (Nepal) guidance on Community-Based Integrated Management of Neonatal and Childhood Illness (IMNCl).

The data captured on the forms includes the following information: unique identifier, date of visit, child's sex, age, ethnicity/caste, weight, temperature, symptoms of general danger signs (GDS), symptoms of acute respiratory infection (ARI) (including respiratory rate), diarrhoea and dehydration symptoms, symptoms for fever and ear infections, mid upper arm circumference (MUAC) measurements, assessment of nutritional status, classification for one major diagnosis, medicine prescribed (name of medicine), follow up plan, and condition of child on the date of follow up.

There were two main versions of the register books in use across the 23 health centres: Integrated Management of Childhood Illness $(\mathrm{IMCl})$ and IMNCl. The two versions of the register books were broadly similar, although there was some variation in the precise format of the forms (e.g. slight differences in the questions or slight differences in the answer options provided in different registers). There were separate forms for children from age two to 59 months, and children below 2 months of age. The differences in questions and answer choices in each type of register are displayed in Supplementary Figure 1. Detailed guidelines were devised by the research team to guide data input and analysis, to ensure definitions of diseases and care protocols were harmonised.

\section{Digitisation of data}

A team of 12 trained Data Entry Assistants entered the data from the images of the paper records into a bespoke data digitisation tool (using KoBo Toolbox [9]), which was designed by members of the project team. At this stage, all data were 
pseudonymised and referred to only by a code number: direct identifiers (such as names and addresses, as well as any other information that could lead to the identification of an individual patient) were not entered into the database.

\section{Data quality checks}

A number of measures were taken to ensure a high standard of data quality. Point-of-entry validation was enforced by checks carried out by the digitisation tool during data entry to ensure mandatory fields were completed, and to prevent entry of invalid data. Data entry verification was conducted by reviewing a sample (5\%) of entered records against the original digital image and any data entry errors were noted and corrected. If consistent errors were identified, this was investigated and all potentially affected records were checked and, where necessary, corrected. Post-entry validation consisted of checks of the data which had already been entered against a set of pre-defined rules to identify potentially invalid, out-of-range, inconsistent or missing data. Where data was not compliant with the validation rules, the discrepancies were highlighted and subsequently reviewed and resolved.

\section{Participants and excluded data}

The IMNCI register books were identified from the sampled health facilities, dated from 2068/05/07 BS (24 August 2011) to 2077/08/12 BS (27 November 2020). Records were collected from 23 rural health posts included in the study. Registers should only be completed for children up to five years of age ( $<60$ months); in the event a child's age was declared as equal to or greater than 60 months, or the age value was missing, the record was excluded from the analysis. For the main analysis we also excluded children whose age's were declared as under 2 months, as we wanted to focus the research on those aged 2 to 59 months. Where the child's sex was not recorded in the register, the sex was inferred based on the child's first name where possible, otherwise it was left as missing. As a sensitivity analysis, we examined the impact of leaving all the undeclared sexes as missing.

\section{Health seeking behaviour and service utilisation}

To assess health seeking behaviour and utilisation of health services, we analysed the number of days the child had symptoms before visiting the health facility for one of the four conditions of interest: acute respiratory infection, diarrhoea, fever, and ear infection. We initially intended to also investigate whether the child attended the health centre for a follow-up; however, as the master registration was not used consistently, it became impossible to track follow-up cases with a lack of data linkage for patients between different clinic attendees.

\section{Assessment of diagnostic accuracy and appropriateness of care}

We assessed the diagnostic accuracy for pneumonia recorded by health workers by comparing their diagnoses with our retrospective diagnosis using the $\mathrm{IMNCl}$ case definition for pneumonia based on the presenting symptoms. We then assessed the appropriateness of treatment for pneumonia by comparing the recorded treatment provided by health workers to children whom they diagnosed as having pneumonia with the IMNCl treatment guidelines.

\section{Statistical Methods}

Descriptive statistics were summarised using count (percentage) and median with Inter-Quartile Range (IQR). The most appropriate hypothesis test was performed to explore unadjusted associations depending on the variable types and distributions (indicated in the footnote of Table 1). To account for the impact of confounding variables, multivariable linear regression was used to assess the number of symptom days a child had ARI, diarrhoea or fever before consultation (ear infection was not modelled due to small numbers). The main predictors of age, sex, ethnicity and district were included in the multivariable model regardless of their univariable significance; the remaining predictors (temperature, whether child was referred to clinic, GDS, ARI, diarrhoea, ear infection and fever) were only included in the multivariable model if their univariable significance was $p<0.20$. Multivariable logistic regression was used to investigate the relationship between demographics and whether the appropriate pneumonia diagnosis and subsequent antibiotic prescription had been provided or not. 
All regression models were analysed as random-effects taking account for the potential clustering of the health facility. In addition to this, multiple imputation (MI) using chained equations was used to impute missing values in all the predictors of interest, with blocks of ten imputations in each regression model, as the primary analysis. As a sensitivity analysis, we also repeated all the regression analyses using only complete case analysis; all sensitivity analyses are presented as supplementary tables.

All inferential analysis is presented with two-sided p-values, where $p<0.05$ was considered statistically significant, and with $95 \%$ confidence intervals. Analyses were performed in Stata version 15.0 [10].

\section{Ethical approval}

A detailed ethical proposal including the tools and methodology for the study was submitted to the Nepal Health Research Council (NHRC). The NHRC review committee reviewed the proposal and granted approval on 13 March 2020, with Ref No: 1936, ERB Protocol No. 12/2020 P. In addition, permission from each health post was gained prior to data collection.

\section{Results}

There were a total of 33,860 child patient records retrieved from a total of $116 \mathrm{IMNCl}$ register books from the 23 rural health posts. Of this total, $643(1.9 \%)$ child patient records from IMNCl forms for children below the age of 2 months were excluded from the analysis. 33,217 records were for children aged 2 to 59 months. $274(0.8 \%)$ records had a recorded age equal to or greater than 60 months, 1,957 (5.9\%) records had missing or unclear age recorded and 255 (0.8\%) records had patient age stated as below 2 months recorded in the 2 to 59 months register; these were all excluded from the analysis. Therefore, 30,731 records were taken forward for analysis (Figure 1).

The median age of children was 16 months (IQR= 9, 30 months), with $92.3 \%$ of children falling into the $2+$ months category. There were more attendances recorded for male children than female children (55.5\% vs $44.2 \%$ ). In terms of ethnic groups, the highest proportion of attendances was for children with Janajati ethnicity (34.9\%), followed by Brahmin/Chhetri (32.3\%). Madhesi and Muslim children comprised only $0.7 \%$ combined, which would be expected given the location of the health centres and the geographical distribution of Madhesi and Muslim population groups, who are mainly concentrated in the Terai (lowland areas) that were not part of this study.

$42 \%$ of children were recorded as having fever, $37 \%$ with diarrhoea, and $34 \%$ with respiratory symptoms. Less than $7 \%$ of children were recorded as having an ear infection, while 2.1\% had General Danger Signs (GDS).

The records from the years 2068 BS (2011/12 AD) ( $n=43), 2069$ BS (2012/13 AD) ( $n=9)$, and 2077 BS (2020/21 AD) ( $n=77)$ were removed from the regression modelling due to convergence issues.

\section{Days of illness prior to presentation at a health centre}

The time interval between onset of symptoms and attendance at a health centre for children with ARI was lowest in Gorkha District with a median of 2 days (IQR=2,3) (Table 1). There were significant differences in time to attendance between the five districts for ARI, diarrhoea and fever with longer delays for Bajura, Mugu and Humla (in the Far West) compared to the other central districts. Janajati children were more likely to attend the health post sooner than children from other ethnic groups for all conditions with the exception of ear infections $(p<0.001)$. There were no significant differences between a child's sex and duration of symptoms prior to attendance for each condition.

Table 1: Median time from symptom onset to attendance at a health centre for young children (age 2-59 months) with ARI, Diarrhoea, Fever and Ear Infection 


\begin{tabular}{|c|c|c|c|c|c|c|c|c|c|c|c|c|}
\hline & \multicolumn{3}{|l|}{ ARI } & \multicolumn{3}{|c|}{ Diarrhoea } & \multicolumn{3}{|l|}{ Fever } & \multicolumn{3}{|c|}{ Ear Infection } \\
\hline & $\mathrm{n}$ & $\begin{array}{l}\text { Med } \\
\text { (IQR) }\end{array}$ & $\mathrm{p}$ & $\mathbf{n}$ & $\begin{array}{l}\text { Med } \\
\text { (IQR) }\end{array}$ & $\mathbf{p}$ & $\mathbf{n}$ & $\begin{array}{l}\text { Med } \\
\text { (IQR) }\end{array}$ & $\mathrm{p}$ & $\mathbf{n}$ & $\begin{array}{l}\text { Med } \\
\text { (IQR) }\end{array}$ & p \\
\hline District & & & $<0.001$ & & & $<0.001$ & & & $<0.001$ & & & 0.350 \\
\hline Sindhupalchowk & 1377 & $\begin{array}{l}3(2 \\
3)\end{array}$ & & 638 & $\begin{array}{l}2(2, \\
3)\end{array}$ & & 1449 & $\begin{array}{l}2(2, \\
3)\end{array}$ & & 1 & $\begin{array}{l}2(2, \\
2)\end{array}$ & \\
\hline Gorkha & 1477 & $\begin{array}{l}2(2 \\
3)\end{array}$ & & 1351 & 2) & & 1619 & 2) & & 0 & - & \\
\hline Humla & 769 & $\begin{array}{l}3(2 \\
5)\end{array}$ & & 994 & $\begin{array}{l}3(2 \\
5)\end{array}$ & & 721 & $\begin{array}{l}3(2 \\
4)\end{array}$ & & 0 & - & \\
\hline Mugu & 1144 & $\begin{array}{l}3(3 \\
5)\end{array}$ & & 1976 & $\begin{array}{l}3(3 \\
5)\end{array}$ & & 1238 & $\begin{array}{l}3(2 \\
4)\end{array}$ & & 0 & - & \\
\hline Bajura & 3679 & $\begin{array}{l}3(2 \\
3)\end{array}$ & & 3480 & $\begin{array}{l}3(2 \\
3)\end{array}$ & & 3481 & $\begin{array}{l}3(2 \\
3)\end{array}$ & & 49 & $\begin{array}{l}3(2 \\
4)\end{array}$ & \\
\hline \multicolumn{13}{|l|}{ Ethnicity } \\
\hline Dalit & 1838 & $\begin{array}{l}3(2 \\
4)\end{array}$ & $<0.001$ & 2007 & $\begin{array}{l}3(2 \\
4)\end{array}$ & $<0.001$ & 1913 & $\begin{array}{l}3(2, \\
3)\end{array}$ & $<0.001$ & 11 & $\begin{array}{l}3(2 \\
5)\end{array}$ & 0.829 \\
\hline Janajati & 2655 & $\begin{array}{l}2(2 \\
3)\end{array}$ & & 2002 & $\begin{array}{l}2(2, \\
3)\end{array}$ & & 2877 & $\begin{array}{l}2(2, \\
3)\end{array}$ & & 2 & $\begin{array}{l}5(2, \\
7)\end{array}$ & \\
\hline Madhesi & 41 & $\begin{array}{l}3(2 \\
4)\end{array}$ & & 54 & $\begin{array}{l}3(3 \\
3)\end{array}$ & & 43 & $\begin{array}{l}3(2, \\
3)\end{array}$ & & 0 & - & \\
\hline Muslim & 13 & $\begin{array}{l}3(2 \\
3)\end{array}$ & & 11 & $\begin{array}{l}3(2 \\
6)\end{array}$ & & 12 & $\begin{array}{l}3 \\
(2.5, \\
3)\end{array}$ & & 0 & - & \\
\hline $\begin{array}{l}\text { Brahmin/ } \\
\text { Chhetri }\end{array}$ & 2885 & $\begin{array}{l}3(2 \\
4)\end{array}$ & & 3212 & $\begin{array}{l}3(2 \\
4)\end{array}$ & & 2828 & $\begin{array}{l}3(2 \\
3)\end{array}$ & & 19 & $\begin{array}{l}3(2, \\
3)\end{array}$ & \\
\hline Others & 931 & $\begin{array}{l}3(2 \\
4)\end{array}$ & & 1103 & $\begin{array}{l}3(2 \\
5)\end{array}$ & & 795 & $\begin{array}{l}3(2 \\
3)\end{array}$ & & 18 & $\begin{array}{l}3(2 \\
5)\end{array}$ & \\
\hline Sex & & & 0.820 & & & 0.945 & & & 0.111 & & & 0.590 \\
\hline Female & 3717 & $\begin{array}{l}3(2 \\
3)\end{array}$ & & 3709 & $\begin{array}{l}3(2 \\
4)\end{array}$ & & 3737 & $\begin{array}{l}2(2 \\
3)\end{array}$ & & 21 & $\begin{array}{l}3(2 \\
3)\end{array}$ & \\
\hline Male & 4714 & $\begin{array}{l}3(2 \\
3)\end{array}$ & & 4721 & $\begin{array}{l}3(2 \\
4)\end{array}$ & & 4760 & $\begin{array}{l}2(2, \\
3)\end{array}$ & & 29 & $\begin{array}{l}3(2 \\
4)\end{array}$ & \\
\hline Total & 8446 & $\begin{array}{l}3(2 \\
3)\end{array}$ & & 8439 & $\begin{array}{l}3(2, \\
4)\end{array}$ & & 8508 & $\begin{array}{l}2(2, \\
3)\end{array}$ & & 50 & $\begin{array}{l}3(2, \\
4)\end{array}$ & \\
\hline
\end{tabular}

Footnote: ARI= Acute Respiratory Infection; IQR= Inter-Quartile Range; All p-values either Mann-Whitney U tests, or Kruskal Wallis ANOVA depending whether comparing 2 or 3 groups.

The unadjusted and adjusted regression results for the number of days a child had ARI, diarrhoea or fever before visiting a health post are presented in Tables 2, 3 and 4 respectively. For ARI, only the Janajati ethnic group was significant in the unadjusted and borderline adjusted models $(p=0.017$ and $p=0.069)$, compared to Dalit children (Table 2): Janajati children with ARI waited on average half a day less than Dalit children before visiting the health post (coef $=-.046,95 \% \mathrm{Cl}:-0.95,0.04)$. Children with ARI from Humla and Mugu in the Far West visited the health post on average one day later than those from Gorkha $(0.76,95 \% \mathrm{Cl}: 0.17,1.35$, and $1.06,95 \% \mathrm{Cl}: 0.45,1.67$ respectively).

Table 2: Univariable and multivariable linear regression of number of ARIs day using multiple imputation analysis 


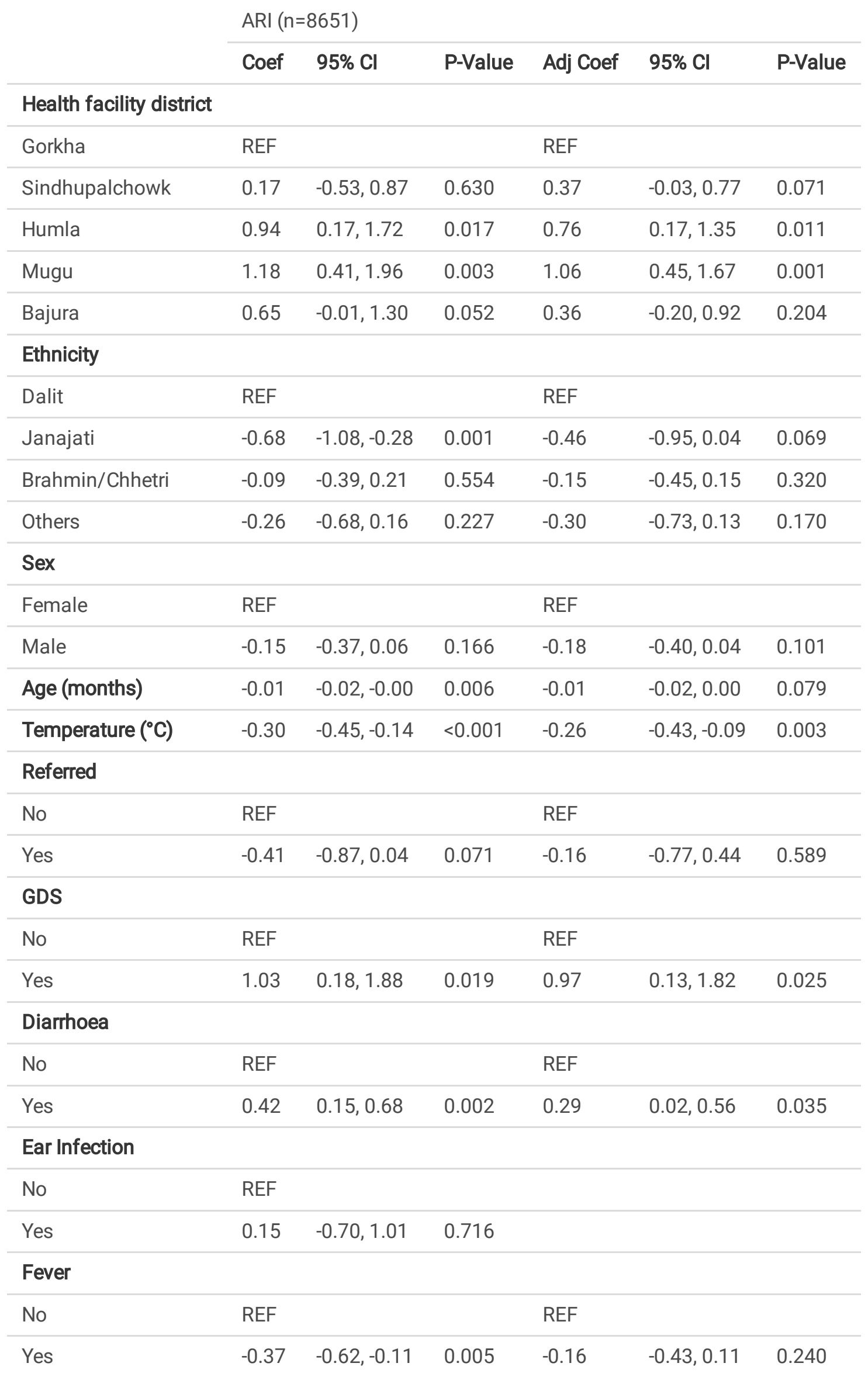

Footnote: Also adjusted for visit year; Muslim and Madhesi removed due to sample size; $A R I=$ Acute Respiratory Infection; $C l=$ Confidence Interval; ${ }^{\circ} \mathrm{C}=$ degrees Celsius; $G D S=$ General Danger Sign; REF= Reference category. 
The time taken to seek help for diarrhoea in those from the Far West (Humla, Mugu and Bajura) was significant in both the unadjusted and adjusted models (all $p \leq 0.02$, Table 3). Children with diarrhoea in Mugu and Humla waited on average 2 days longer to visit the health post $(2.01,95 \% \mathrm{Cl}: 1.24,2.78$ and $1.94,95 \% \mathrm{Cl}: 1.23,2.78$ respectively) than those in Gorkha.

Table 3: Univariable and multivariable linear regression of number of diarrhoea days using multiple imputation analysis 
Diarrhoea $(n=8660)$

\section{Coef $\quad 95 \% \mathrm{Cl} \quad$ P-Value Adj Coef $95 \% \mathrm{Cl} \quad$ P-Value}

\section{Health facility district}

\begin{tabular}{|c|c|c|c|c|c|c|}
\hline Gorkha & REF & & & REF & & \\
\hline Sindhupalchowk & 0.12 & $-0.43,0.67$ & 0.667 & 0.12 & $-0.46,0.70$ & 0.690 \\
\hline Humla & 2.00 & $1.52,2.48$ & $<0.001$ & 1.94 & $1.23,2.66$ & $<0.001$ \\
\hline Mugu & 2.00 & $1.60,2.40$ & $<0.001$ & 2.01 & $1.24,2.78$ & $<0.001$ \\
\hline Bajura & 0.86 & $0.49,1.22$ & $<0.001$ & 0.87 & $0.15,1.58$ & 0.017 \\
\hline \multicolumn{7}{|l|}{ Ethnicity } \\
\hline Dalit & REF & & & REF & & \\
\hline Janajati & -1.20 & $-1.66,-0.74$ & $<0.001$ & -0.42 & $-1.07,0.23$ & 0.205 \\
\hline Brahmin/Chhetri & -0.40 & $-0.74,-0.07$ & 0.017 & -0.50 & $-0.83,-0.17$ & 0.003 \\
\hline Others & -0.66 & $-1.12,-0.21$ & 0.004 & -0.80 & $-1.25,-0.35$ & $<0.001$ \\
\hline \multicolumn{7}{|l|}{ Sex } \\
\hline Female & REF & & & REF & & \\
\hline Male & -0.02 & $-0.24,0.27$ & 0.903 & 0.02 & $-0.23,0.27$ & 0.874 \\
\hline Age (months) & -0.01 & $-0.02,0.00$ & 0.088 & -0.01 & $-0.02,0.00$ & 0.267 \\
\hline Temperature $\left({ }^{\circ} \mathrm{C}\right)$ & -0.23 & $-0.42,-0.03$ & 0.022 & -0.23 & $-0.42,-0.04$ & 0.021 \\
\hline \multicolumn{7}{|l|}{ Referred } \\
\hline No & REF & & & & & \\
\hline Yes & 0.39 & $-0.28,1.05$ & 0.241 & & & \\
\hline \multicolumn{7}{|l|}{ GDS } \\
\hline No & REF & & & & & \\
\hline Yes & 0.44 & $-0.42,1.29$ & 0.317 & & & \\
\hline \multicolumn{7}{|l|}{ ARI } \\
\hline No & REF & & & & & \\
\hline Yes & -0.03 & $-0.32,0.26$ & 0.836 & & & \\
\hline
\end{tabular}

\section{Ear Infection}

\begin{tabular}{llll} 
No & REF & & \\
\hline Yes & -0.02 & $-0.94,0.89$ & 0.958 \\
\hline Fever & & & \\
No & REF & & \\
Yes & -0.07 & $-0.34,0.24$ & 0.627
\end{tabular}

Footnote: Also adjusted for visit year; Muslim and Madhesi removed due to sample size; $A R I=$ Acute Respiratory Infection; $C l=$ Confidence Interval; ${ }^{\circ} \mathrm{C}=$ degrees Celsius; $G D S=$ General Danger Sign; REF= Reference category. 
District, sex, presence of GDS and ARI were significantly associated with time delay to presentation for fever in the adjusted model (all $\mathrm{p} \leq 0.02$, Table 4). Children with fever from Humla $(1.16,95 \% \mathrm{Cl}: 0.75,1.57)$, Mugu $(0.78,95 \% \mathrm{Cl}: 0.36,1.20)$ and Bajura $(0.57,95 \% \mathrm{Cl}: 0.19,0.95)$ waited significantly longer than those from Gorkha. Similarly, females waited longer before visiting a health post than males $(\mathrm{p}=0.02)$.

Table 4: Univariable and multivariable linear regression of number of fever days using multiple imputation analysis 
Fever $(\mathrm{n}=2462)$

\section{Coef $95 \% \mathrm{Cl} \quad$ P-Value Adj Coef $95 \% \mathrm{Cl} \quad$ P-Value}

\section{District}

\begin{tabular}{lcccccc}
\hline Gorkha & REF & & \multicolumn{3}{c}{ REF } \\
\hline Sindhupalchowk & -0.01 & $-0.35,0.33$ & 0.958 & 0.01 & $-0.30,0.31$ & 0.972 \\
\hline Humla & 1.24 & $0.85,1.63$ & $<0.001$ & 1.16 & $0.75,1.57$ & $<0.001$ \\
\hline Mugu & 0.84 & $0.47,1.22$ & $<0.001$ & 0.78 & $0.36,1.20$ & $<0.001$ \\
\hline Bajura & 0.59 & $0.27,0.92$ & $<0.001$ & 0.57 & $0.19,0.95$ & 0.003
\end{tabular}

Ethnicity

\begin{tabular}{lcccccc}
\hline Dalit & REF & \multicolumn{5}{c}{ REF } \\
\hline Janajati & -0.41 & $-0.64,-0.18$ & 0.001 & -0.11 & $-0.39,0.17$ & 0.434 \\
\hline Brahmin/Chhetri & -0.01 & $-0.17,0.15$ & 0.858 & -0.03 & $-0.19,0.13$ & 0.681 \\
\hline Others & -0.06 & $-0.29,0.17$ & 0.620 & -0.10 & $-0.33,0.14$ & 0.415
\end{tabular}

Sex

\begin{tabular}{llllllll}
\hline Female & REF & & & REF & & \\
Male & -0.14 & $-0.26,-0.03$ & 0.016 & -0.14 & $-0.25,-0.02$ & 0.020 \\
\hline Age (months) & 0.00 & $0.00,0.00$ & 0.696 & 0.00 & $0.00,0.01$ & 0.257 \\
\hline Temperature $\left({ }^{\circ} \mathrm{C}\right)$ & -0.01 & $-0.15,0.01$ & 0.069 & -0.07 & $-0.16,0.01$ & 0.068 \\
\hline Referred & & & & & & \\
\hline No & REF & & & REF & & 0.099 \\
\hline Yes & -0.19 & $-0.43,0.06$ & 0.127 & -0.20 & $-0.43,0.04$ & \\
\hline GDS & & & & & & \\
\hline No & REF & & & REF & & \\
\hline Yes & 1.16 & $0.39,1.93$ & 0.005 & 1.12 & $0.35,1.88$ & 0.007 \\
\hline ARI & & & & & & \\
\hline No & REF & & & REF & & \\
\hline Yes & 0.18 & $0.06,0.31$ & 0.004 & 0.17 & $0.05,0.29$ & 0.007 \\
\hline Diarrhoea & & & & & & \\
\hline No & REF & & & REF & & \\
\hline Yes & 0.18 & $0.05,0.32$ & 0.006 & 0.12 & $-0.02,0.26$ & 0.087 \\
\hline
\end{tabular}

Ear Infection

$\begin{array}{llll}\text { No } & \text { REF } & & \\ \text { Yes } & 0.09 & -0.25,0.42 & 0.611\end{array}$

Footnote: Also adjusted for visit year; Muslim and Madhesi removed due to sample size; $A R I=$ Acute Respiratory Infection; $C l=$ Confidence Interval; ${ }^{\circ} \mathrm{C}=$ degrees Celsius; $G D S=$ General Danger Sign; REF= Reference category. 
As mentioned previously, due to issues with accuracy of data completion for follow-up, it was not possible to formally analyse this part of the information. The main reasons were that children were infrequently allocated a Master Registration Number (MRN), akin to a unique ID for that child, and even when they were, there were issues of accuracy (sometimes the same number appeared for two different children of different sexes). We have included the information we could from the registers in Supplementary Table 2.

\section{Correct diagnosis and treatment of pneumonia}

For the children for whom we were able to retrospectively diagnose pneumonia from their presenting symptoms, $22.0 \%$ had no pneumonia; $62.9 \%$ had pneumonia and $15.0 \%$ had severe pneumonia (based on IMNCI guidelines). However, among all children whose pneumonia was diagnosed by the health worker, $65.3 \%$ had no pneumonia, $34.0 \%$ had pneumonia and $0.7 \%$ had severe pneumonia. The accuracy of pneumonia diagnoses by the health worker could only be analysed for 2,548 children due to missing data in variables necessary to assess the diagnosis of pneumonia retrospectively from the records. Pneumonia was not correctly diagnosed in 30\% of children. Children from the Madhesi and Dalit ethnic group were less likely to have a correct diagnosis of pneumonia (36.4\% and $66.3 \%$ respectively). Male children were significantly more likely to be correctly diagnosed for pneumonia (73.3\% vs $67 \%)$.

Of the 2,663 children who were recorded as having severe pneumonia or pneumonia by the health worker, over $60 \%$ were not provided correct treatment in line with the IMNCl guidelines (Table 5).

Children in the Janajati group had the lowest proportion of correct treatment whereas the highest proportion receiving correct treatment was seen for Dalit children (34.1\% vs $41 \%$ ). This excludes Madhesi and Muslim children that were not included in the subsequent regression analysis due to the small numbers.

Table 5: Pneumonia correctly diagnosed and correct treatment provided by health worker 
Pneumonia correctly diagnosed

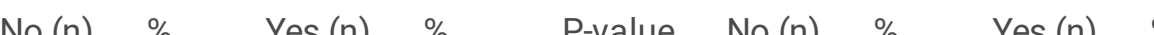

\begin{tabular}{lccccccccccc} 
& No $(\mathrm{n})$ & $\%$ & Yes $(\mathrm{n})$ & $\%$ & P-value & No $(\mathrm{n})$ & $\%$ & Yes $(\mathrm{n})$ & $\%$ & P-value \\
\hline Ethnicity & & 33.8 & 371 & 66.3 & $0.014^{\star}$ & 305 & 59.0 & 212 & 41.0 & $0.185^{\star}$
\end{tabular}

Dalit $\quad 189$

\begin{tabular}{lllll}
\hline Janajati & 197 & 29.1 & 479 & 70.9 \\
\hline Madhesi & 7 & 63.6 & 4 & 36.4 \\
\hline Muslim & 0 & 0.0 & 5 & 100.0 \\
\hline Brahmin/Chhetri & 283 & 28.1 & 724 & 71.9 \\
\hline Others & 72 & 27.1 & 194 & 72.9 \\
\hline
\end{tabular}

\section{Sex}

Female

Male

Referred

\begin{tabular}{|c|c|c|c|c|c|c|c|c|c|c|}
\hline No & 339 & 30.6 & 770 & 69.4 & \multirow[t]{2}{*}{0.002} & 714 & 66.1 & 366 & 33.9 & \multirow[t]{2}{*}{$<0.001$} \\
\hline Yes & 50 & 44.6 & 62 & 55.4 & & 32 & 42.7 & 43 & 57.3 & \\
\hline \multicolumn{5}{|l|}{ GDS } & \multirow[t]{3}{*}{$<0.001$} & & & & & \multirow[t]{3}{*}{0.532} \\
\hline Yes & 122 & 91.0 & 12 & 9.0 & & 47 & 64.4 & 26 & 35.6 & \\
\hline No & 548 & 26.1 & 1554 & 74.9 & & 1328 & 60.8 & 858 & 39.3 & \\
\hline \multicolumn{5}{|l|}{ ARI } & \multirow[t]{3}{*}{0.599} & & & & & \multirow[t]{3}{*}{$<0.001$} \\
\hline Yes & 702 & 29.9 & 1645 & 70.1 & & 1456 & 61.4 & 914 & 38.6 & \\
\hline No & 45 & 28.0 & 116 & 72.0 & & 124 & 76.5 & 38 & 23.5 & \\
\hline \multicolumn{5}{|l|}{ Diarrhoea } & \multirow[t]{3}{*}{0.313} & & & & & \multirow[t]{3}{*}{0.432} \\
\hline Yes & 181 & 28.1 & 464 & 72.9 & & 406 & 62.5 & 244 & 37.5 & \\
\hline No & 513 & 30.2 & 1186 & 69.8 & & 1044 & 60.7 & 676 & 39.3 & \\
\hline \multicolumn{5}{|l|}{ Ear Infection } & \multirow[t]{3}{*}{0.013} & & & & & \multirow[t]{3}{*}{0.305} \\
\hline Yes & 33 & 41.3 & 47 & 58.8 & & 45 & 65.2 & 24 & 34.8 & \\
\hline No & 588 & 28.4 & 1484 & 71.6 & & 1246 & 59.1 & 864 & 41.0 & \\
\hline \multicolumn{5}{|l|}{ Fever } & \multirow[t]{3}{*}{$<0.001$} & & & & & \multirow[t]{4}{*}{$<0.001$} \\
\hline Yes & 444 & 26.7 & 1222 & 73.4 & & 1055 & 59.6 & 715 & 40.4 & \\
\hline No & 254 & 34.9 & 474 & 65.1 & & 449 & 67.8 & 213 & 32.2 & \\
\hline Total & 756 & 29.7 & 1792 & 70.3 & & 1696 & 63.7 & 967 & 36.3 & \\
\hline
\end{tabular}

Footnote: All p-values Chi-square test unless marked with a * ${ }^{*}=$ Fishers Exact Test); $A R I=$ Acute Respiratory Infection; ${ }^{\circ} \mathrm{C}=$ degrees Celsius; GDS= General Danger Sign.

Janajati children had $77 \%$ higher odds of a correct pneumonia diagnosis compared to Dalit children (Odds Ratio $(\mathrm{OR})=1.77$, $95 \% \mathrm{Cl}: 1.11,2.84)$ after adjusting for background factors, while children with higher body temperatures also had $20 \%$ higher 
odds (OR=1.20,95\% Cl: $1.05,1.37)$ (Table 6$)$. Males had significantly higher odds of a correct diagnosis than females $(\mathrm{OR}=1.29$, $95 \% \mathrm{Cl}: 1.06,1.57)$.

Table 6: Unadjusted and adjusted logistic regression results of correct diagnosis of pneumonia vs not (reference) and correct treatment of pneumonia vs not (reference) using multiple imputation analysis 


\begin{tabular}{|c|c|c|c|c|c|c|c|c|c|c|c|c|}
\hline & \multicolumn{6}{|c|}{ Correct diagnosis of Pneumonia $(n=2,611)$} & \multicolumn{6}{|c|}{ Correct treatment of Pneumonia $(n=1,739)$} \\
\hline & OR & $\begin{array}{l}95 \% \\
\mathrm{Cl}\end{array}$ & $\begin{array}{l}\text { P- } \\
\text { Value }\end{array}$ & AOR & $\begin{array}{l}95 \% \\
\mathrm{Cl}\end{array}$ & $\begin{array}{l}\mathrm{P}- \\
\text { Value }\end{array}$ & OR & $\begin{array}{l}95 \% \\
\mathrm{Cl}\end{array}$ & $\begin{array}{l}\text { P- } \\
\text { Value }\end{array}$ & AOR & $\begin{array}{l}95 \% \\
\mathrm{Cl}\end{array}$ & $\begin{array}{l}\text { P- } \\
\text { Value }\end{array}$ \\
\hline \multicolumn{13}{|l|}{ District } \\
\hline Gorkha & REF & & & REF & & & REF & & & REF & & \\
\hline Sindhupalchowk & 1.22 & $\begin{array}{l}0.57 \\
2.63\end{array}$ & 0.603 & 1.13 & $\begin{array}{l}0.52 \\
2.46\end{array}$ & 0.764 & 4.05 & $\begin{array}{l}1.11 \\
14.85\end{array}$ & 0.035 & 2.64 & $\begin{array}{l}0.62 \\
11.29\end{array}$ & 0.191 \\
\hline Humla & 0.98 & $\begin{array}{l}0.43 \\
2.27\end{array}$ & 0.970 & 1.31 & $\begin{array}{l}0.51 \\
3.34\end{array}$ & 0.572 & 2.00 & $\begin{array}{l}0.48 \\
8.27\end{array}$ & 0.339 & 1.48 & $\begin{array}{l}0.29 \\
7.64\end{array}$ & 0.638 \\
\hline Mugu & 3.34 & $\begin{array}{l}1.39 \\
8.03\end{array}$ & 0.007 & 5.20 & $\begin{array}{l}1.91 \\
14.20\end{array}$ & 0.001 & 7.68 & $\begin{array}{l}1.89 \\
31.17\end{array}$ & 0.004 & 4.56 & $\begin{array}{l}0.87 \\
23.77\end{array}$ & 0.072 \\
\hline Bajura & 1.31 & $\begin{array}{l}0.65 \\
2.66\end{array}$ & 0.447 & 1.66 & $\begin{array}{l}0.71 \\
3.86\end{array}$ & 0.239 & 2.96 & $\begin{array}{l}0.89 \\
9.87\end{array}$ & 0.078 & 3.94 & $\begin{array}{l}0.91 \\
17.01\end{array}$ & 0.066 \\
\hline \multicolumn{13}{|l|}{ Ethnicity } \\
\hline Dalit & REF & & & REF & & & & & & REF & & \\
\hline Janajati & 1.29 & $\begin{array}{l}0.87 \\
1.91\end{array}$ & 0.208 & 1.77 & $\begin{array}{l}1.11 \\
2.84\end{array}$ & 0.017 & 1.15 & $\begin{array}{l}0.69 \\
1.91\end{array}$ & 0.603 & 1.37 & $\begin{array}{l}0.76 \\
2.47\end{array}$ & 0.291 \\
\hline Brahmin/Chhetri & 1.16 & $\begin{array}{l}0.92 \\
1.47\end{array}$ & 0.202 & 1.19 & $\begin{array}{l}0.92 \\
1.54\end{array}$ & 0.182 & 1.13 & $\begin{array}{l}0.85 \\
1.50\end{array}$ & 0.405 & 1.13 & $\begin{array}{l}0.82 \\
1.55\end{array}$ & 0.459 \\
\hline Others & 0.90 & $\begin{array}{l}0.63 \\
1.28\end{array}$ & 0.550 & 0.84 & $\begin{array}{l}0.56 \\
1.24\end{array}$ & 0.371 & 0.87 & $\begin{array}{l}0.57 \\
1.33\end{array}$ & 0.514 & 0.91 & $\begin{array}{l}0.56 \\
1.48\end{array}$ & 0.693 \\
\hline \multicolumn{13}{|l|}{ Sex } \\
\hline Female & REF & & & REF & & & REF & & & REF & & \\
\hline Male & 1.36 & $\begin{array}{l}1.14 \\
1.62\end{array}$ & 0.001 & 1.29 & $\begin{array}{l}1.06 \\
1.57\end{array}$ & 0.011 & 0.89 & $\begin{array}{l}0.71 \\
1.11\end{array}$ & 0.287 & 0.85 & $\begin{array}{l}0.67 \\
1.09\end{array}$ & 0.202 \\
\hline Age (months) & 1.00 & $\begin{array}{l}0.99 \\
1.00\end{array}$ & 0.525 & 1.00 & $\begin{array}{l}0.99 \\
1.00\end{array}$ & 0.413 & 1.00 & $\begin{array}{l}0.99 \\
1.01\end{array}$ & 0.794 & 1.00 & $\begin{array}{l}0.99 \\
1.01\end{array}$ & 0.453 \\
\hline $\begin{array}{l}\text { Temperature } \\
\left({ }^{\circ} \mathrm{C}\right)\end{array}$ & 1.23 & $\begin{array}{l}1.11 \\
1.38\end{array}$ & $<0.001$ & 1.20 & $\begin{array}{l}1.05 \\
1.37\end{array}$ & 0.008 & 1.04 & $\begin{array}{l}0.91 \\
1.18\end{array}$ & 0.570 & & & \\
\hline \multicolumn{13}{|l|}{ Referred } \\
\hline No & REF & & & & & & REF & & & REF & & \\
\hline Yes & 0.97 & $\begin{array}{l}0.66 \\
1.44\end{array}$ & 0.887 & & & & 4.82 & $\begin{array}{l}3.04 \\
7.64\end{array}$ & $<0.001$ & 1.60 & $\begin{array}{l}0.80 \\
3.21\end{array}$ & 0.177 \\
\hline \multicolumn{13}{|l|}{ GDS } \\
\hline No & REF & & & REF & & & REF & & & & & \\
\hline Yes & 0.03 & $\begin{array}{l}0.01 \\
0.05\end{array}$ & $<0.001$ & 0.02 & $\begin{array}{l}0.01 \\
0.05\end{array}$ & $<0.001$ & 1.28 & $\begin{array}{l}0.29 \\
5.62\end{array}$ & 0.736 & & & \\
\hline \multicolumn{13}{|l|}{ ARI } \\
\hline No & REF & & & & & & REF & & & & & \\
\hline Yes & 0.84 & $\begin{array}{l}0.57 \\
1.23\end{array}$ & 0.370 & & & & 1.18 & $\begin{array}{l}0.47 \\
3.01\end{array}$ & 0.724 & & & \\
\hline Diarrhoea & & & & & & & & & & & & \\
\hline
\end{tabular}




\begin{tabular}{|c|c|c|c|c|c|c|c|c|c|c|c|c|}
\hline No & REF & & & & & & REF & & & & & \\
\hline Yes & 0.98 & $\begin{array}{l}0.79 \\
1.21\end{array}$ & 0.842 & & & & 0.93 & $\begin{array}{l}0.71 \\
1.22\end{array}$ & 0.618 & & & \\
\hline \multicolumn{13}{|c|}{ Ear Infection } \\
\hline No & REF & & & REF & & & REF & & & & & \\
\hline Yes & 0.51 & $\begin{array}{l}0.32 \\
0.83\end{array}$ & 0.007 & 0.62 & $\begin{array}{l}0.36 \\
1.07\end{array}$ & 0.086 & 0.58 & $\begin{array}{l}0.24 \\
1.43\end{array}$ & 0.233 & & & \\
\hline \multicolumn{13}{|c|}{ Fever } \\
\hline No & REF & & & REF & & & REF & & & REF & & \\
\hline Yes & 1.57 & $\begin{array}{l}1.29 \\
1.90\end{array}$ & $<0.001$ & 1.60 & $\begin{array}{l}1.28 \\
2.00\end{array}$ & $<0.001$ & 1.32 & $\begin{array}{l}1.01 \\
1.72\end{array}$ & 0.039 & 1.44 & $\begin{array}{l}1.07 \\
1.92\end{array}$ & 0.015 \\
\hline
\end{tabular}

Footnote: Also adjusted for visit year; Muslim and Madhesi removed due to sample size; $A O R=$ Adjusted Odds Ratio; $A R I=$ Acute Respiratory Infection; $\mathrm{Cl}=$ Confidence Interval; ${ }^{\circ} \mathrm{C}=$ degrees Celsius; $G D S=$ General Danger Sign; OR= Odds Ratio; REF= Reference category.

Associations with correct treatment of pneumonia (given they had been diagnosed) were not so plentiful, with no significant difference in ethnicity, sex or age (all $p>0.2$ ). The only significant relationship was with a current diagnosis of fever with $44 \%$ higher odds (OR=1.44, 95\% Cl: 1.07, 0.192) and a borderline significant relationship with children in the Mugu district compared to Gorkha (OR=4.56, 95\% Cl: 0.87, 23.77).

\section{Sensitivity analyses}

The complete case regression models (Supplementary Tables 3-6) produced similar conclusions to the multiple imputation models, although the $\mathrm{Ml}$ regression models frequently included more variables in the final multivariable model. Excluding all the 828 children who did have a sex declared as missing from the analysis only subtly changed the estimates and did not impact any conclusions.

\section{Discussion}

In this large secondary analysis of children under 5 in Nepal, we have highlighted that there are some significant differences between health seeking behaviours and particular demographics such as ethnicity, sex, and in some cases age. In addition, there appeared to be some more clear differences in achieving a successful diagnosis of pneumonia based on the child's ethnicity, sex and District even after accounting for background factors; however, these differences were not as apparent when examining subsequent treatment for pneumonia.

It is not surprising that inequalities in health and healthcare amongst under-5 children exist in remote rural areas of Nepal as this mirrors similar experience from around the world [11]. The determinants are manifold and have been previously described [12], including key factors such as the accessibility [13] and availability of services [14]. One proposed solution has been the provision of care closer to home that may help address the accessibility issue [15]. However, our study highlights that proximity of services is not enough as even with village-level health posts there remain significant differences in patient health seeking behaviour as well as quality of care provision. Alarmingly, there were high percentages of misdiagnosis of pneumonia and suboptimal treatment subsequently. Ethnic differences were observed with children from the Dalit ethnic group having low ratios for correct diagnosis of pneumonia. Paradoxically, they were more likely to receive correct treatment than the other ethnic groups. Reasons for this are not clear from our data and could be the focus of valuable future research. There was some difference observed in accuracy of diagnosis but not treatment for pneumonia by sex, while the child's age was not associated with the correct diagnosis or treatment of pneumonia.

\section{Comparisons to wider literature}


As reported elsewhere [16], we found delays in health seeking were associated with district, with patients in less-developed districts in the Far West presenting later than those in the relatively more developed districts in the central region of the country. Likewise, there were greater delays seen for older children than younger children. There were also greater delays in seeking treatment seen for lower caste ethnic groups, which mirrors previously reported lower service utilisation rates for maternal healthcare in Nepal $[17,18]$. Part of the explanation for this may be cultural but socioeconomic barriers such as poverty cannot be discounted.

The WHO put forward in 2006 the Treat, Train, Retain strategy to address the skills and health workforce shortages in lowincome countries [19]. A central pillar of this strategy is task shifting some of the health work to less specialised community health workers. However, the low accuracy of diagnosis and correct treatment of pneumonia even by trained community-level health workers found in our study puts this approach in doubt. Indeed, the figures were not much better compared to reported rates of disease recognition by caregivers [20]. Suboptimal care is likely to lead to poorer health outcomes and undermine efforts to improve child mortality rates in developing countries such as Nepal. Similar issues have been reported elsewhere [21]. This highlights the need for greater efforts, through training and supportive supervision, to improve the clinical performance of frontline community health workers [22].

The other notable finding was that correct diagnoses for pneumonia tended to be made in the presence of a fever. This could reflect the challenge of diagnosing pneumonia based on subtler and more subjective symptoms than fever. This again highlights a training need for frontline staff to better recognise respiratory infections that may not present with a febrile illness.

We also note that disease recognition by health workers showed a two-fold difference between the lowest caste and higher caste patient groups. This cannot be explained by economic or physical access factors. Similarly, there was a gender disparity with more correct diagnoses and treatment of pneumonia in males than females. The reasons for both of these observations are not clear and warrant further study.

\section{What the study adds}

Our study demonstrates that there is utility in further and regular analysis of secondary data from primary care settings, including in low- and middle-income countries. The absence of electronic health information systems in rural Nepali health centres inhibits such analysis, with the collection and digitisation of paper-based records being a time-consuming and resource-intensive task. In addition, the analysis of this data is highly dependent on the availability of clinical records that in turn rely on the diligence of health workers recording patient consultations. This data can help inform and guide local service delivery, as well as audit clinical practice as part of service improvement initiatives. However, in keeping with routinely collected clinical data, there will be limitations in terms of accuracy, completeness and timeliness of the data. Some of the limitations are set out below.

\section{Limitations}

Firstly, there was no consistent tracking of individual patients between visits to a health centre (although there is a field on the form for MRN number, this is often not used - or used inaccurately) so the same children could have visited the health post more than once, yet appear in the data as if they are separate patients. This limitation also meant we could not ascertain the outcomes of consultations beyond prescribing/onward referral. There was also no way to ascertain whether what was recorded by staff was accurately recorded and a true reflection of the clinical picture for the patients attending the clinics. There may also be other confounding factors that we could not control for that we were not aware of such as staff turnover or potential contaminating effects of local training and supervision that may have taken place. In our assessment of the diagnostic accuracy of acute respiratory infections, we are making a presumption that the syndromic approach espoused in the $\mathrm{IMNCl}$ guidelines is accurate. However, it is recognised that not all febrile illnesses will be due to infections and that there are a wide range of diagnostic possibilities in young children with febrile illnesses.

\section{What are the implications?}


One key insight emerging from our study is the need for good quality monitoring of healthcare activity as part of quality assurance. This is difficult currently based on existing paper records that are not collated or interrogated, and in which it is not possible to reliably track individual children and study follow-up behaviour or health outcomes. Switching from a paper-based record to digital record system may help address these issues, as well as containing fewer recording errors that can occur compared to handwritten records. We have previously demonstrated that it is possible to introduce basic electronic patient record systems even in low-income country settings like Nepal [23].

Our study confirms that there are geographical and sociodemographic inequalities in health-seeking behaviour as well as care provision in rural areas. We identify an important need to raise awareness amongst parents of danger symptoms and signs, especially in certain districts and ethnic groups where awareness levels may be low, so that ill children attend health facilities sooner. We also observed that health workers seem to respond more to some symptoms such as illnesses where there is fever present. They may consequently not appreciate fully serious illnesses where there is no fever. Further training may be needed focused on non-febrile illnesses that may be life-threatening conditions. We also observed a gender bias to health seeking behaviour, with greater delay seen for female children. Therefore, further public education on gender equality remains important.

\section{Conclusions}

The causes of continuing health inequalities in Nepal, and in other low and middle-income countries, are multi-faceted and complex - and relate to a great extent to the social and economic determinants. Nevertheless, more fully understanding how differences in geography, sex, ethnicity and caste affect health seeking behaviours and the quality of diagnosis and treatment received following presentation to a health facility is an important step in more fully understanding (and subsequently remedying) inequalities in health service utilisation and quality. The findings of this study identify a range of observed inequalities that can be followed up through detailed qualitative research. The inability to carry out such analysis on an ongoing, routine basis as a result of the absence of electronic record keeping represents an obstacle to identifying and further investigating such inequalities.

\section{Abbreviations}

ARI

Acute Respiratory Infection

GDS

General Danger Signs

HMIS

Health Management and Information System

IMCI

Integrated Management of Childhood IIIness

$\mathrm{IMNCl}$

Integrated Management of Neonatal and Childhood Illness

IQR

Inter-Quartile Range

MI

Multiple Imputation

MRN

Master Registration Number

MUAC

Mid Upper Arm Circumference

NHRC

Nepal Health Research Council 
Non-Governmental Organisation

OR

Odds Ratio

WHO

World Health Organisation

\section{Declarations}

Ethics approval and consent to participate

A detailed ethical proposal including the tools and methodology for the study was submitted to the Nepal Health Research Council (NHRC). The NHRC review committee reviewed the proposal and granted approval on 13 March 2020, with Ref No: 1936, ERB Protocol No. 12/2020 P. In addition, permission from each health post was gained prior to data collection.

Consent for publication

Availability of data and materials

The final dataset (with explanatory documentation) is available from the UK Data Service via (website will be provided after peer-review as this would reveal the authors/research team)

Competing interests

A number of the authors work, or formerly worked, for PHASE Nepal, the Nepali health, education and livelihood NGO that runs or supports the health posts that provided the data for this study (see affiliations).

Funding

This study was funded by the UK Economic and Social Research Council's GCRF NGO Secondary Data Analysis Initiative (Grant Ref: ES/T010436/1).

Authors' contributions:

All authors designed and implemented the study. BS, MB and DJG led on the statistical analysis. All authors contributed to and approved the final, submitted version of the manuscript.

\section{Acknowledgements}

The authors would like to thank the staff at PHASE Nepal who collected and processed the registers from the health posts (Usha Singh and Saraswati Adhikari), and those who digitalised the data from the registers (Anita Dhoju, Anjana Poudel, Anup Gupta, Ashmita Thapa, Barsha Yogi, Bhagwati Rana, Chandani Singh Nakarmi, Devaki Karki, Sabnam Karki, Samita Lamsal, Sangita Majhi, Sukunj Tamang). In addition, Usha Singh contributed to the initial analysis.

\section{References}

1. UNDP. 2020. Gender Inequality Index. Data available at http://hdr.undp.org/en/content/gender-inequality-index-gii. Accessed 10 Jan 2022.

2. Angdembe MR, Dulal BP, Bhattarai K, Karn S. Trends and predictors of inequality in childhood stunting in Nepal from 1996 to 2016. Int J Equity Health. 2019;18:42. 
3. Nepali S, Simkhada P, Davies I. Trends and inequalities in stunting in Nepal: a secondary data analysis of four Nepal demographic health surveys from 2001 to 2016. BMC Nutrition. 2019;5:19.

4. Subedi M. Caste/Ethnic Dimensions of Change and Inequality: Implications for Inclusive and Affirmative Agendas in Nepal. Nepali Journal of Contemporary Studies. 2016;16:1-16.

5. WHO. Inequality in Reproductive, Maternal and Child Health in Nepal. Regional Office for South-East Asia, 2016. https://apps.who.int/iris/handle/10665/279779. Accessed 10 Jan 2022.

6. Kattel S, McNeil N, Tongkumchu P. Social determinants of linear growth among under five years children in Nepal. Pertanika J Soc Sci Humanit. 2017;25:851-9.

7. Akhtar R. Child healthcare in Nepal: Progress and direction. Am J Public Health Res. 2015;3:74-80.

8. Maru S, Nirola I, Thapa A, Thapa P, Kunwar L, Wu W-J, Halliday S, Citrin D, Schwarz R, Basnett I, KC N, Karki K, Chaudhari P, Maru D. An integrated community health worker intervention in rural Nepal: a type 2 hybrid effectiveness-implementation study protocol. Implement Sci. 2015;13:53.

9. KoBo Toolbox. Official website https://www.kobotoolbox.org/. Accessed 06 Jan 2022.

10. StataCorp. 2021. Stata Statistical Software: Release 17. College Station, TX: StataCorp LLC.

11. Fagbamigbe AF, Kandala NB, Uthman AO. Demystifying the factors associated with rural-urban gaps in severe acute malnutrition among under-five children in low-and middle-income countries: A decomposition analysis. Sci Rep. 2020;10:1-5.

12. Jacobs B, Ir P, Bigdeli M, Annear PL, Van Damme W. Addressing access barriers to health services: an analytical framework for selecting appropriate interventions in low-income Asian countries. Health Policy Plann. 2012;27:288-300.

13. Cabieses B, Bird P. Glossary of access to health care and related concepts for low- and middle-income countries (LMICs): A critical review of international literature. Int J Health Serv. 2014;44:845-61.

14. Peters DH, Garg A, Bloom G, Walker DG, Brieger WR, Rahman MH. Poverty and access to health care in developing countries. Ann N Y Acad Sci. 2008;1136:161-71.

15. Bright T, Felix L, Kuper H, Polack S. A systematic review of strategies to increase access to health services among children in low and middle income countries. BMC Health Serv Res. 2017;17:1-9.

16. Kironji AG, Hodkinson P, De Ramirez SS, Anest T, Wallis L, Razzak J, Jenson A, Hansoti B. Identifying barriers for out of hospital emergency care in low and low-middle income countries: a systematic review. BMC Health Serv Res. 2018;18:1-20.

17. Khanal V, Bhandari R, Adhikari M, Karkee R, Joshi C. Utilization of maternal and child health services in western rural Nepal: a cross-sectional community-based study. Indian J Public Health. 2014;58:27.

18. Dhakal S, Chapman GN, Simkhada PP, Van Teijlingen ER, Stephens J, Raja AE. Utilisation of postnatal care among rural women in Nepal. BMC Pregnancy Childb. 2007;7:1-9.

19. WHO 2007. Taking stock: task shifting to tackle health worker shortages. Geneva: World Health Organisation; https://www.who.int/healthsystems/task_shifting/TTR_tackle.pdf?ua=1. Accessed 06 Jan 2022.

20. Tupasi TE, Miguel CA, Tallo VL, Bagasao TM, Natividad JN, Valencia LB, De Jesus ME, Lupisan S, Medalla F. Child care practices of mothers: implications for intervention in acute respiratory infections. Ann Trop Paediatr 1989;9:82-8.

21. Stekelenburg J, Kyanamina SS, Wolffers I. Poor performance of community health workers in Kalabo District, Zambia. Health Policy. 2003;65:109-18.

Page 20/21 
22. Bellerose M, Alva S, Magalona S, Awoonor-Williams K, Sacks E. Supervision of community health nurses in Ghana: a mixed-methods study on experiences and mentorship needs. Health Policy Plann. 2021;36:720-7.

23. Watkinson-Powell A, Lee A. Benefits of an electronic medical records system in rural Nepal. J Nepal Med Assoc 2012;52:196-200.

\section{Figures}

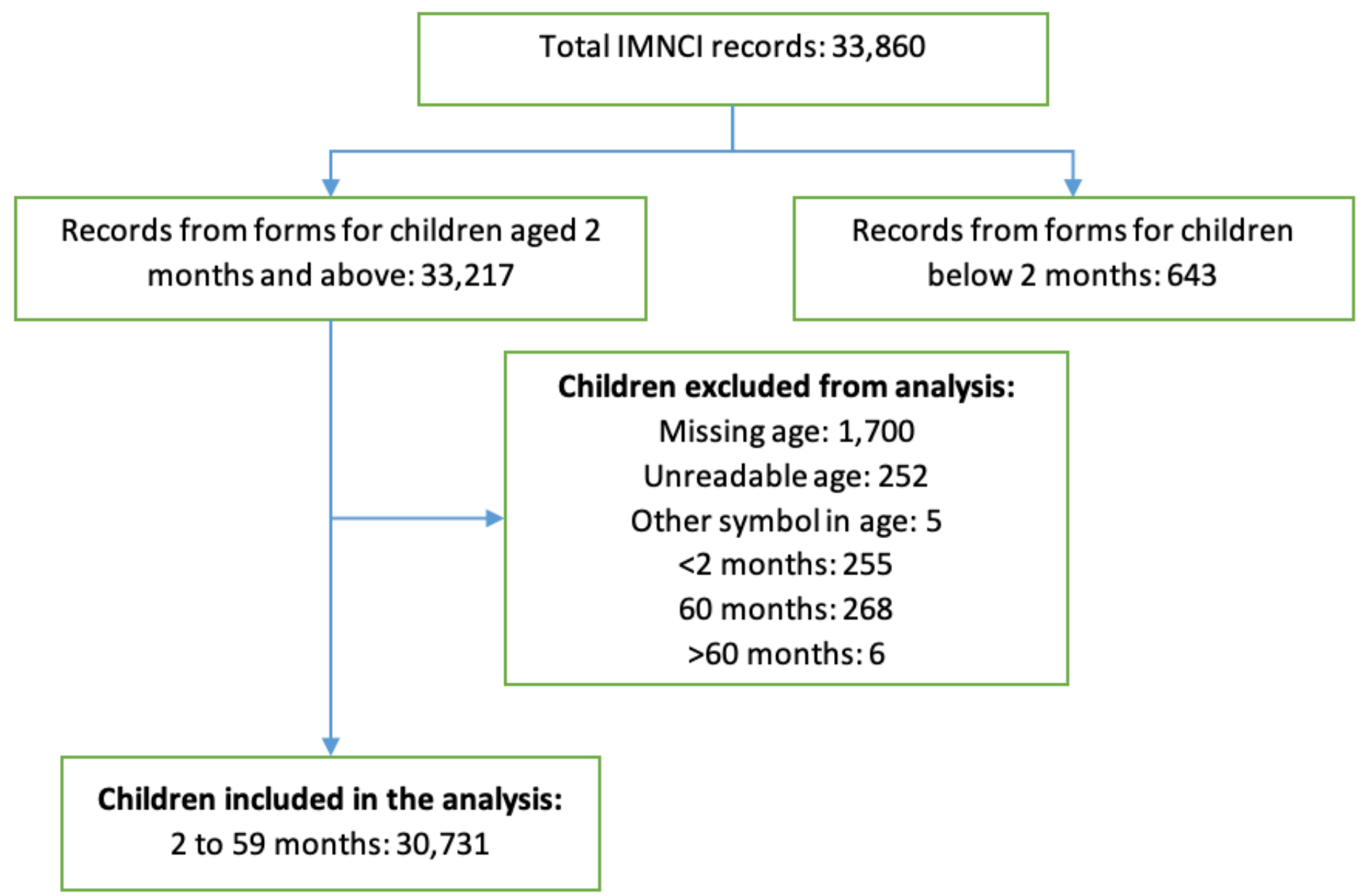

Figure 1

Flow diagram illustrating the number of records identified, and those carried forward for analysis, with reason for exclusion noted

\section{Supplementary Files}

This is a list of supplementary files associated with this preprint. Click to download.

- SupplementaryInformation.docx 